\title{
IMPACT OF SITUATIONAL AND PROPOSITIONAL TIME FLOW ON MONETARY SAVING PROPOSITION MADE IN THE FIRST- AND THE THIRD-PERSON PERSPECTIVE
}

\author{
Oleksiy POLUNIN \\ Visiting researcher at the Institute of Experimental Psychology \\ Center of Social and Psychological Sciences, Slovak Academy of Sciences \\ Dúbravská cesta 9, 81364 Bratislava, Slovak Republic \\ Permanent affiliation: Faculty of Economics, Management, and Psychology, \\ Kyiv National University of Trade and Economics, \\ vul. Kioto 19, Kyiv, 00200 Ukraine \\ E-mail: polunin-alex@yandex.ua
}

\begin{abstract}
The study examines the properties of cognitive representations of situational and propositional time flow in relation to the first- and the third-person perspective on monetary saving proposition. The subjects made decisions whether to accept a monetary saving proposition. Despite the equal distance to the beginning of saving possibility and equality of saving amounts the subjects made significantly different decisions depending on whether a situational or a propositional time flow was activated. The newly found temporal framing effect (Polunin, 2015) was confirmed and its new version for the propositions formulated from the third-person perspective is described. The results specify the features of situational and propositional time flow and the consequent discrepancies in the decision outcomes. In general, the discounting of the saving proposition made from the first- and the third-person perspective runs slower when situational time flow is activated.
\end{abstract}

Key words: decision making, time representation, temporal framing, personal perspective, monetary saving

\section{Introduction}

Personal perspective on an event and its extension in time are two key factors in social interactions. Both impact the evaluation of an event and the intensity of different interpersonal exchanges - the goods ex-

Acknowledgement

The research stay at the Institute of Experimental Psychology of the Slovak Academy of Sciences and this study was supported by the grant from the National Scholarship Programme of the Slovak Republic. change, money transaction or harmonization of political plans. Fruitful social transactions would be impossible if human mind could not produce both: first- and third-person perspectives on one and the same object or relation. Distinguishing between personal perspective and perspective taken by of others is fundamental for social communication (Decety \& Sommerville, 2003). One's own goals and attitudes are expressed from the first person perspective (1PP), while the goals and attitudes of others are presented as the third-person perspective (3PP). So, for a moment an individual human mind should be able to identify itself with others. This

DOI: $10.21909 / \mathrm{sp} .2016 .03 .715$ 
ability helps to plan one's own behavior and contributes to a more optimal communicative action. A number of the social interactions extend over time, e.g., money depositing, securing future income or planning of future family life. Economic transactions like investing in the stock market and planning a corporate investment are also realized in time dimension and depend on cognitive representation of time flow. As shown in the studies by Loewenstein (1988) there are different ways to frame a decision in time dimension, thus, the properties of time dimension of human experience may have an impact on such actions. Therefore, we examined the variation of subjective acceptability of one and the same monetary saving proposition depending on a) the personal perspective (1PP vs. 3PP) and b) on the representation of proposition in time. So, an impact of the firstand the third-person perspectives on monetary proposition and its variation over time are of interest in this study.

\section{Cognitive Representations of Time Flow: Situational and Propositional Time}

In cognitive sciences time flow is conventionally conceptualized as linear, homogeneous and equal for all objects. But one can raise the question: is a subject served well just by one cognitive representation of time flow? Must the time flow be represented in the mind exclusively as a singular temporal process? The indications of the mind's ability to develop few cognitive representations of time flow can be found in an implicit form in the studies by Chen (2013) and Read et al. (2005). Chen (2013) has shown that languages differ widely in the ways they encode time. He has proved the hypothesis that those languages that grammatically associ- ate the future and the present, foster futureoriented behavior. According to Chen (2013), the speakers of such languages: 'save more, retire with more wealth, smoke less, practice safer sex, and are less obese'. This finding holds both across countries and within countries when comparing demographically similar native households. Read et al. (2005) have shown that one and the same future proposition but once marked by the calendar date and the other time as time delay induce different preferences. In conclusion they state: the description of a temporal interval affects discounting of proposition. But describing this paradox they avoid an explicit assumption about the minds ability to produce more than one representation of time flow.

Based on Freyd's (1987) assumption about the temporal dimension of a mental representation, a temporal variable was introduced into a topical account paradigm (Polunin, 2009). By varying it, a number of temporal processes were distinguished: past openness, aging in the past and future time mode, and zero probability barrier in the future time mode (Polunin, 2009, 2011). Each of them has specific properties and, therefore, is as a separate temporal process to consider. A temporal process is defined as a change of an object-representation over time in one qualitative domain, e.g., its subjective attractiveness. Such change reflects a specific development of object over time but without change of its identity. So, we suggest that the human mind is able to model a multitude of temporal processes applying each of them to one and the same object (Polunin, 2011), e.g., to money proposed for saving. Applying different temporal processes to the same monetary saving proposition one might get different cognitive representations of the same proposition and consequently - dif- 
ferent decision outcomes (Polunin, 2015). It means that a subjective value of one unit of money (e.g., 1 EUR) changes differently depending on the temporal process it underlies to. Moreover, it also means a diversity of individual behavior reactions to the same proposition depending on the currently actualized representation of time flow.

In our earlier study (Polunin, 2015), additionally to the mentioned above temporal processes, we distinguished between cognitive representations for propositional and situational time flow. Propositional future means a time perspective when time flow is considered only for an object (a proposition). This kind of time flow may be activated when an object is directly connected to time flow, e.g., for an electoral choice the following wording may be applied: "Will you vote for Mr. X as president, when he gets 3 years older?". Or in the case of consumer decision making one may apply the following wording of the propositional time flow: "Will you buy wine "X", when it gets 3 years older?". Under situational future we understand a general time flow, when a cognitive representation of a situation is modelled as a whole at the future time moment. Due to the special wording one causes a kind of mental "jump" into the future situation. For instance, one can apply the following wording of an electoral choice, "imagine, in 3 years you are going to vote for a president, whom you would vote for?". Mathematically there is no difference between these two kinds of future as long as the time distance from the reference moment to the future moment is the same. But because of the special wording of the problem it is possible to activate separately the propositional and the situational time flow (Read et al., 2005; Polunin, 2015). So, one and the same future proposition receives two ways of presentation.

Due to the discrepancy between the situational and propositional time flow a new kind of a temporal framing effect arises (Polunin, 2015). Temporal framing effect means that the subject makes different decisions on mathematically equal propositions just because a time mark is set once on the situation as a whole and the other time just on the monetary saving proposition. The cognitive representations of time flow for a situation as a whole and that for a saving proposition subjectively seem to be essentially different. In this study we expect to confirm this finding. But the main goal of the current study is to specify the properties of the situational and propositional time flows regarding the firstperson- and the third-person-perspective on a saving proposition. This specification should contribute to further distinguishing of these two cognitive representations of time flow, examining how far they differ. When one considers: 1) that the propositional future expresses an explicit waiting process and 2) based on the previously found similarity in the properties of the situational future and the present time mode, one may assume that the monetary saving proposition formulated in the situational future may show stronger preference than the same proposition formulated in the propositional future (hypothesis 1). So, in general the saving proposition should be more attractive in the situational time flow than in the propositional time flow.

One may point to the number of other publications highlighting the different kinds of temporal framing effects, especially within the studies on intertemporal decision making (Chandran \& Menon, 2004; Loewenstein, 1988; Mazur, 1987; Prelec \& Loewenstein, 1997). Here we consider the framing of a de- 
cision problem to be its wording in different ways but without change of the essence. Thus, the time dimension of the decision problem, despite different wordings, keeps the same mathematical description: the problem belongs to the same time mode, time distance and time direction being also the same within the wordings. It is in this strict sense that we are mentioning the temporal framing effect in the current paper. But one has to consider, that this strict definition is not always held in the other studies on temporal framing, e.g., in some studies one varies the processed distances between the time moment of decision making and a moment of decision outcome or one changes the order of proposition processing (Loewenstein, 1988); in the other studies temporal framing is manifested because of different time horizons applied in the wording of the tasks (Chandran \& Menon, 2004). In some studies temporal framing is interpreted as the application of present- vs. future-oriented messages, which in fact breaks the equality of time mode between two problem wordings and, moreover, it is rather a broad understanding of temporal framing (Kim \& Nan, 2015). That is not the case for the time parameters used in this paper as well as in our previous study (Polunin, 2015).

\section{Representation of Proposition for Self and Other over Time as Source of its Attractiveness Variation}

The competition for resources and monetary gains are extended in time (Mowen \& Mowen, 1991) and their evaluation varies essentially depending on personal perspective, e.g., the valuation of losses for self differs from that for the other (Krishnamurthy $\&$ Kumar, 2002). Thus, how one thinks about time flow in the other's mind predefines the readiness to follow monetary saving proposition or to refuse it. The central source of discrepancy between the first and the thirdperson perspectives can be overconfidence, namely the better-than-average effect, which means the tendency for most people to see themselves as smarter or more skilled than average (Brown, 1986; Taylor \& Brown, 1988; Haslam et al., 2005; Klar \& Giladi, 1997). People tend to make favorable assessments of their own abilities in many aspects (Alicke, 1985; Dunning et al., 1989). Klar and Giladi (1997) in their work have shown the existence of a positive bias with which a subject usually judges him/herself over the group's average. So, studies on human overconfidence provide evidence for overestimating one's own abilities, knowledge and accuracy of one's own actions. Thus, another student's actions taken as a third person are, on average, underestimated in comparison to the subject acting from the first person perspective. In our previous study (Polunin, 2014) we already determined that the other student is seen as poorer and thus as more sensitive to the saving propositions formulated in the present time mode. Subjects show a higher acceptance of the monetary saving proposition made in the name of the third person than the acceptance of the same proposition but made from the first person perspective. In the current study we make a similar assumption (hypothesis 2.1): in the present time mode because of the overconfidence a subject will demonstrate a lower readiness to follow the saving proposition formulated from the first-person-perspective (1PP) than for the same proposition but formulated from the third-person perspective (3PP). Assuming the general character of the overconfidence one should expect the same 
tendency for the decision outcomes by activation of both - the situational and propositional time flow in future time mode. In general, the smaller monetary saving proposition should be sufficiently attractive for the other person (3PP), while for oneself (1PP) the proposition must be higher to be accepted. This asymmetry between the 1PP and 3PP decision outcomes should be true under all conditions, when it is explained by the better-than-average effect. One has just to consider the relative amount of the monetary saving (Moon, Keasey, \& Duxbury, 1999; Polunin, 2014). When a propositional time flow is activated, the low and high relative saving propositions show different patterns of attractiveness in the future time mode.

The situational future time shows almost the same properties as the present time, at least for the time distance of a few days (Polunin, 2015). Thus, for the situational time flow we expect the decision outcomes to be quite similar to those in the present time mode for both the 1PP and 3PP (hypothesis 2.2). For the propositional time flow the picture should be slightly different because a monetary saving proposition usually shows a discount when this kind of time flow is activated. The attractiveness of the saving proposition made to the first-person (1PP) declines and the number of positive responses should decline as well. When one makes the same proposition to the third person (3PP) one should expect the same kind of decline of the proposition attractiveness. But we do not know how strong this discounting will be. The better-than-average effect may point to the higher attractiveness of a proposition to the 3PP and so to a smaller decline, but here the level of absolute and relative saving is in play predefining the ve- locity of decline. Krishnamurthy and Kumar (2002) have shown that the self-other discrepancy emerges in choices involving an explicit waiting time risk. People are more generous with the time of the others than with their own time. So, (hypothesis 2.3) one cannot exclude the possibility that for the propositional time flow, which most explicitly models the waiting, one can find a higher number of positive responses for the $3 \mathrm{PP}$ but not for the self(1PP). In hypothesis 1 we have assumed that in the present time mode the 3PP proposition should show a higher number of positive responses than the 1PP. So, because of the different starting positions in the present time mode, and because of the different levels of discounting they (the 1PP and 3PP given in the propositional time flow) may even reach the same level of attractiveness in few days of the future time mode. So, one can expect a discrepancy between the situational and propositional time flow, and not only for the 1PP-problem formulation but also for the problem formulated from the 3PP.

\section{Experiment}

\section{Method}

As the experimental task, a problem situation was taken in which a student is going to buy a pair of shoes. The proposed absolute monetary saving was $45 \mathrm{UAH}^{1}$. In one wording of the problem the whole situation was

\footnotetext{
${ }^{1}$ UAH or Ukrainian hryvna, the exchange rate during the data collection was: 1 EUR $=17.20$ UAH (sell), 1 EUR = 18.50 UAH (buy); 1 USD = 12.40 UAH (sell), 1 USD $=13.30$ UAH (buy). The saving of $45 \mathrm{UAH}$ equals approximately 2.50 EUR or 3.50 USD.
} 
Table 1 The design of the experiment. The original price was $545 \mathrm{UAH}$, the absolute price reduction was $45 \mathrm{UAH}$. The relative saving in all cases was the same and equal to $8.26 \%$. The independent variables are: representation of the future (situational vs. propositional) and personal perspective on the monetary saving proposition (1PP vs. 3PP). As the base-line condition serves the present-time condition, "Now". The subject's decision outcomes were taken as the dependent variable.

\begin{tabular}{|c|c|c|c|}
\hline \multirow[t]{2}{*}{ Personal perspective } & \multirow{2}{*}{$\begin{array}{c}\text { Now, } \\
0 \text { days distance }\end{array}$} & \multicolumn{2}{|c|}{$\begin{array}{c}\text { Future, } \\
6 \text { days distance }\end{array}$} \\
\hline & & Situational & Propositional \\
\hline $1^{\text {st }}$ person perspective (1PP) & $545-45=500 \mathrm{UAH}$ & $545-45=500 \mathrm{UAH}$ & $545-45=500 \mathrm{UAH}$ \\
\hline $3^{\text {rd }}$ person perspective (3PP) & $545-45=500 \mathrm{UAH}$ & $545-45=500 \mathrm{UAH}$ & $545-45=500 \mathrm{UAH}$ \\
\hline
\end{tabular}

moved to 6 days in the future. In the other wording of the problem only the beginning of a saving opportunity was in 6 days in the future while the situation as whole was given in the present time mode. So, the independent variable has two sides: situational vs. propositional future monetary saving. A monetary saving proposition formulated in the present time mode was taken as the baseline condition. In addition to the time variable, personal perspective was also varied (1PP vs. 3PP). For modelling of the third person perspective our subject (a first person) was asked to make a decision for a third per$\mathrm{son}^{2}$. The subjects made decisions whether the other student accepts the saving proposition or not. The absolute (45 UAH), and relative $(8.26 \%)$ monetary saving, and the initial price of the pair of shoes (545 UAH) were the same in all problem wordings. Each subject got only one wording of the deci-

\footnotetext{
${ }^{2}$ In this study another student of the same year of study was taken as the third person, so that the $1^{\text {st }}$ and the $3^{\text {rd }}$ person have a comparably equal monthly income and are equal in their stage of study.
}

sion problem. The between subjects experimental design was applied, which is usual for such studies (Tversky \& Kahneman, 1981; Kühberger, 1998; Levin et al., 1998). The design of the experiment is given in the Table 1.

By such design one has to consider the possible effect of sunk-cost, which may affect the decision outcomes. In a previous study (Polunin, 2015) we combined the situational and propositional time flow tasks at one waiting distance -7 days. The whole 7 days distance was decomposed in 2 ways: once 5 situational waiting days +2 propositional waiting days $(5 s+2 p=7)$, and the other time 2 situational waiting days +5 propositional waiting days $(2 s+5 p=7)$. Since in both cases the propositional time flow is involved, the sunk-cost is the same in both decomposed conditions. Despite equal sunkcost the impact of situational and propositional time flow on the proposition's acceptability remains essentially different and leads to the described temporal framing effect. So, the temporal framing effect is not explained by the sunk-cost but by the discrepancy between the situational and propositional time 
flow. Therefore, in this study we rely rather on the essential discrepancy between the situational and propositional time flow than on the sunk-cost effect. The sunk-cost effect under the current design may be seen as rather the difference between the presenttime condition and the situational future condition, which is not of interest in this study.

\section{Materials}

Written versions of the problem were prepared in Ukrainian. Similar wording was used in each experimental condition and only the way of referring to the time moment (present time, situational future and propositional future) and personal perspective (1PP vs. 3PP) was varied. In the task wordings the time distance was underlined to make it more explicit. The participants were asked to mark their decision by checking the corresponding box. The amount of monetary saving remained always the same. For the present time mode the saving proposition was given "now", within the same day. For the condition "first-person perspective in the future time mode" the tasks were formulated as follows.

Task for activation of the situational time flow, future time mode, 1PP.

Imagine the following situation and decide how you will act.

Please imagine that in 6 days you will go to the shop to purchase a pair of shoes for 545 UAH. When you choose the shoes and go to the cash desk a shop assistant informs you that the shoes you wish to buy are on sale for $500 \mathrm{UAH}$ at the other branch of the store, located 20 minutes drive away.

Would you make the trip to the other store? (check one box)

YES $\square$

NO $\square$
Task for activation of propositional time flow, future time mode, $1 P P$.

Imagine the following situation and decide how you will act.

Please imagine that you went to a shop to purchase a pair of shoes for $545 \mathrm{UAH}$. When you choose the shoes and go to the cash desk a shop assistant informs you that the shoes you wish to buy will in 6 days be on sale for $500 \mathrm{UAH}$ at the other branch of the store, located 20 minutes drive away.

Would you make the trip to the other store? (check one box)

\section{YES $\square$ \\ NO $\square$}

For the condition "third-person perspective in the future time mode" the tasks were formulated as follows.

Task for activation of situational time flow, future time mode, 3PP.

Imagine the following situation and decide how a student of the same year will act.

Please imagine that in 6 days a student will go to a shop to purchase a pair of shoes for $545 \mathrm{UAH}$. When the student chooses the shoes and goes to the cash desk a shop assistant informs him that the shoes he wishes to buy are on sale for $500 \mathrm{UAH}$ at the other branch of the store, located 20 minutes drive away.

Would the student make the trip to the other store? (check one box)

YES $\square$

\section{NO $\square$}

Task for activation of propositional time flow, future time mode, $3 P P$.

Imagine the following situation and decide how a student of the same year will act.

Please imagine that a student went to a shop to purchase a pair of shoes for 545 UAH. When he chooses the shoes and goes to the cash desk a shop assistant in- 
forms him that the shoes he wishes to buy will in 6 days be on sale for $500 \mathrm{UAH}$ at the other branch of the store, located 20 minutes drive away.

Would the student make the trip to the other store? (check one box)

$$
\text { NO }
$$

One may notice that the way a subject has to make a decision to accept the monetary saving proposition has different number of "stops" for situational and propositional time conditions. For the propositional time model a subject has to travel the route: homeshop1-home-shop2-home. But for the situational time model the travelling is one "stop" shorter: home-shop1-shop2-home. Since the distances and directions are not given in the task, and the three points "home", "shop 1", and "shop 2" can be connected in a threemillions city in many ways, the subjects, while reading the problem description, may randomly interpret the costs along both ways. Also, one cannot exclude that "shop 2" may be easier to reach from home than "shop 1". Thus, we assume that the impact of the way-factor as not very influential. Moreover, as it was mentioned above the decomposition of the whole way in two components (situational and propositional) does not eliminate the temporal framing effect (Polunin, 2015) and obviously it is not the key factor for the studied phenomenon, at least with the given level of savings.

\section{Subjects}

558 students (93 subjects for each of the six experimental conditions) between the ages of 17 and 25 (mean age 19.2 years, $S D=$ 0.98 ; $76 \%$ males and $24 \%$ females) participated in the experiment. The participation was voluntary and unpaid. The students were randomly ascribed to one of six experimental conditions. Each subject solved only one decision problem and none of the subjects participated in the experiment repeatedly. The number per session ranged from 12 to 36 subjects. Among the participants were only students of technical faculties majoring in electro-mechanics, robotics, electro-technical studies and in applied physics. The subjects had no special knowledge of the expected utility theory, sunk-cost effect or framing of decision making.

\section{Results}

Despite the fact that in all experimental conditions every student has a possibility to save the same amount of money, the decision outcomes are different. The percentage of positive responses to the monetary saving proposition is presented in Table 2 . The general effect of the personal perspective across all experimental conditions is significant, Pearson Chi-Square, $\chi^{2}=13.99, \mathrm{df}=1$, $p<0.001$. Over all conditions the percent of positive responses for the $1 \mathrm{PP}$ equals to $53.8 \%$, while for the 3PP it equals to $69.2 \%$. Making the decision from the 1PP a subject decides whether the monetary saving is sufficiently attractive for him/herself. In case of decision making from the $3 \mathrm{PP}$ a subject has to assess whether the other subject will accept a saving proposition. Hypothesis 1 has been proved, in general the monetary saving proposition is seen as more attractive for the other person ( $3^{\text {rd }}$ person), while for the self ( $1^{\text {st }}$ person $)$ the same proposition is less acceptable. The very bottom row in Table 2 shows the discrepancy between the 1PP and 3PP under three time moments (present, situational future and propositional future). The 
discrepancy between the $1 \mathrm{PP}$ and $3 \mathrm{PP}$ reaches statistical significance for both the situational $(p=0.025)$ and the propositional future $(p=0.001)$, but is non-significant for the present time mode $(p=0.36)$. The highest discrepancy in the acceptance of the saving proposition between the 1PP and 3PP is reached when the propositional time flow is activated, $\Delta=24.8 \%$.

An impact of a time flow representation can be shown through the change of attractiveness of the monetary saving proposition over time. In Table 2 one can see that two representations of time flow contribute differently to the proposition acceptance in the future time mode. The general effect of the time flow representation in the future time mode (situational vs. propositional future) across both $1 \mathrm{PP}$ and $3 \mathrm{PP}$ experimental conditions is significant, Pearson Chi-Square, $\chi^{2}=15.3, \mathrm{df}=1, p<0.001$. The percent of positive responses for the situational future equals to $69.9 \%$, while for the propositional future it equals to $50 \%$. So in general, independently of personal perspective, one can argue that the saving proposition looses its attractiveness to a lesser degree when it is "placed" in the situational time flow than when it is "placed" in the propositional time flow. Saying it metaphorically, the situational time flows essentially slower than the propositional one, therefore a proposition made in the situational time flow keeps its high attractiveness much longer.

The discrepancy between the situational and propositional time flow can be demonstrated from two perspectives: 'dynamic', when one compares the decline of the saving proposition attractiveness caused by each of the time flow representations, and

Table 2 The percentage of positive responses to the saving proposition under each experimental condition. As "now" is given the present time condition. The temporal framing effect is given in the most right column as a comparison of decision outcomes for the situational and propositional future: $\Delta=$ Situat. Future - Propos. Future.

\begin{tabular}{|c|c|c|c|c|c|c|}
\hline \multirow[t]{2}{*}{$\begin{array}{l}\text { Personal } \\
\text { perspective }\end{array}$} & \multirow{2}{*}{$\begin{array}{c}\text { Now, } \\
0 \text { days } \\
\text { distance }\end{array}$} & \multicolumn{2}{|c|}{$\begin{array}{c}\text { Future, } \\
6 \text { days distance }\end{array}$} & \multicolumn{3}{|c|}{$\begin{array}{c}\text { Difference in \% of "yes" responses over the time } \\
\text { moment representations }\end{array}$} \\
\hline & & Situational & Propositional & $\begin{array}{l}\Delta=\text { Now-Situat. } \\
\quad \text { Future }\end{array}$ & $\begin{array}{c}\Delta=\text { Now-Propos. } \\
\text { Future }\end{array}$ & $\begin{array}{c}\text { Framing effect, } \\
\Delta=\text { Situat. Future } \\
\text { - Propos. Future }\end{array}$ \\
\hline 1PP & $61.3 \%$ & $62.4 \%$ & $37.6 \%$ & $\begin{array}{c}\Delta=-1.1 \% \\
\chi^{2}=0.023, \\
\mathrm{df}=1, \\
\mathrm{p}=0.88, \text { (n.s.) }\end{array}$ & $\begin{array}{c}\Delta=\mathbf{2 3 . 7 \%} \\
\chi^{2}=10.4 \\
\mathrm{df}=1 \\
\boldsymbol{p}=\mathbf{0 . 0 0 1}\end{array}$ & $\begin{array}{c}\Delta=\mathbf{2 4 . 8} \% \\
\chi^{2}=11.37 \\
\mathrm{df}=1 \\
\boldsymbol{p}=\mathbf{0 . 0 0 1}\end{array}$ \\
\hline 3PP & $67.7 \%$ & $77.4 \%$ & $62.4 \%$ & $\begin{array}{c}\Delta=-9.7 \% \\
\chi^{2}=2.18 \\
\mathrm{df}=1, \\
\mathrm{p}=0.14, \text { (n.s.) }\end{array}$ & $\begin{array}{c}\Delta=5.3 \%, \\
\chi^{2}=0.6, \\
\mathrm{df}=1, \\
\mathrm{p}=0.44, \text { (n.s.) }\end{array}$ & $\begin{array}{c}\Delta=\mathbf{1 5 \%} \\
\chi^{2}=5 \\
\mathrm{df}=1 \\
p=\mathbf{0 . 0 2 5}\end{array}$ \\
\hline $\begin{array}{l}\text { in } \% \\
3 \mathrm{PP}-1 \mathrm{PP}\end{array}$ & $\begin{array}{c}\Delta=6.4 \%, \\
\chi^{2}=0.85, \\
d f=1, \\
p=0.36 \text { (n.s.) }\end{array}$ & $\begin{array}{c}\Delta=\mathbf{1 5} \% \\
\chi^{2}=5 \\
\mathrm{df}=1 \\
p=\mathbf{0 . 0 2 5}\end{array}$ & $\begin{array}{c}\Delta=\mathbf{2 4 . 8 \%} \\
\chi^{2}=11.37, \\
\text { df }=1, \\
p=0.001\end{array}$ & - & - & - \\
\hline
\end{tabular}


'static', when one compares the attractiveness of the proposition at one and the same time moment ( 6 days in future) but modelled once as situational and the other time as propositional future (see three right hand columns in Table 2). The right hand column (Table 2) presents the size of the corresponding temporal framing effect.

The decline of the proposition attractiveness for the 1PP wording is the strongest under the impact of the propositional time flow $\left(\Delta=23.7 \%, \chi^{2}=10.4, \mathrm{df}=1, p=0.001\right)$. The situational time flow does not lead to the decrease of proposition attractiveness at all. One can speak even about the nonsignificant increase of attractiveness $(\Delta=$ $\left.-1.1 \%, \chi^{2}=0.023, \mathrm{df}=1, p=0.88\right)$. So, the situational and propositional time flows demonstrate different properties and this discrepancy provides the basis for the temporal framing effect. For the 3PP the decline of positive responses under the impact of the situational and propositional time flow does not reach the level of significance. Statistically, they lead to almost the same preference for the monetary saving proposition. But the situational and propositional time flow clearly shows the opposite tendencies in the dynamics of proposition attractiveness. Due to the situational time flow the monetary saving proposition gains in the attractiveness $(+9.7 \%)$, while the propositional time flow leads to a small decrease $(-5.3 \%)$. Also, in this case one can specify the properties of the situational and propositional time flow as being different. Based on this difference the temporal framing effect arises for the 3PPproposition wordings as well.

A comparison of the responses to the future saving proposition in the 6 days, once formulated within the situational and the other time within the propositional time flow, shows significant discrepancy for both personal perspectives - for the 1PP $\Delta=24.8 \%, \chi^{2}=$ 11.37, $\mathrm{df}=1, p=0.001$ and for the $3 \mathrm{PP} \Delta=$ $15 \%, \chi^{2}=5, \mathrm{df}=1, p=0.025$. The discrepancy in positive responses for the $1 \mathrm{PP}$ is the new kind of the temporal framing effect described earlier (Polunin, 2015), when the subjects show different preferences for mathematically equal proposition given in the same distance in the future. The current results show that a similar effect exists also for the 3PP. But the rise of this temporal framing effect for the 3PP-proposition is predefined rather through the increase of positive responses under the impact of situational time flow than the decrease of positive responses under the propositional time flow. This creates the difference between the temporal framing effects for the 3PP and the 1PP wordings of the monetary saving proposition.

\section{Discussion}

The previously found new kind of the temporal framing effect, which is based on the discrepancy between situational and propositional time flows, was confirmed for the propositions formulated from the first person perspective. The current results point to the existence of a similar temporal framing effect for the monetary saving proposition made for the third person. In both cases the framing effect arises because subject's attention was focused once on time distance to a future monetary gain and the other time on the future moment of the gain. Correspondingly, this activates the cognitive representations for the propositional and situational time flows. Despite the fact that in both cases the waiting time for a monetary saving is the same, the subjects demonstrate an essentially different acceptance of the 
saving proposition. The human mind more easily makes a mental "jump" from one situation in time to the other than pursuing a slow object related time flow, e.g., while waiting for a sell-out of a certain item. Thus, one can argue that the representations of the situational and propositional time flows have different properties. Since one and the same representation of time flow cannot show different properties in relation to one and the same object (amount of money) the current findings support the thesis about the mind's ability to develop multiple representations of time flow (Polunin, 2009, 2011, 2015). On account of the discrepancies in the properties of these time flow representations, one and the same unit of money going through the same time distance changes its subjective value differently. In the current case the change of attractiveness of the monetary saving is predefined through: a) the personal perspective, and b) the actual time flow representation (situational vs. propositional). The unit of money discounts slowly in the situational time flow, but the slowest discounting can be found when the money is proposed on the part of the other person. In this case the discounting even reverses into a small increase of the money value.

The new kind of the temporal framing broadens the list of temporal framing effects presented by Lowenstein (1988). Also, the previously proposed classification of the temporal processes (Polunin, 2011) considers only the propositional time flow and thus it must be expanded by the representation of the situational time flow. The branch representing the situational time flow must be further divided into two sub-branches presenting the first- and the third-person perspectives. So, the idea of the mind's ability to develop few representations of time flow is getting further empirical support. We can share the thought expressed by Read et al. (2005), our findings should serve as a caution to researchers modelling the events and processes in time dimension. Researchers usually choose temporal descriptions for arbitrary or pragmatic reasons. Yet they will then propose as general truths findings that apply only to the particular representation of time flow they arbitrarily or pragmatically chose, sometimes without being aware that there are many of them.

Chen (2013) has proved a close link between the future presentation in the language people speak and their economic decisions. When one looks at the study by Chen (2013), one can gains the interpretation that the described two types of future representation in different languages are quite similar to the situational and propositional future in our study. In this sense the language just reflects the ability of the human mind to develop more than one representation of time flow. Both, our results and the findings by Chen (2013) show that the different representations of time flow result in different economic decisions. Thus, one has to critically look at the conventional concept of singular time flow. Possibly one day we will be ready to introduce the concept of the multiple cognitive representations of time flow in the modelling of human behavior.

There are already neuropsychological findings pointing to the different brain structures for processing of the propositions given in the present and the future time mode. Using fMRI McClure et al. (2004) examined the neural correlates of time discounting and found that two separate neural systems are involved in such decisions. An immediately available reward is processed by the parts of the lim- 
bic system in association with the midbrain dopamine system and paralimbic cortex. The delayed propositions are processed by the lateral prefrontal cortex and posterior parietal cortex. In the light of the current findings on the discrepancy between the situational and propositional future it seems to be worth to study their neural correlates. One can examine the discrepancies in the neural activity while processing the representations of the present time and the situational future. In this and in the previous study we come to the conclusion, that the situational time flow, at least at the distance of few days, shows almost no difference to the present time mode. Both lead to quite similar decision outcomes. Possibly the situational future time representation relies on the similar neuronal system as the representation of the present time mode. On the other hand the propositional future time representation may be processed by the other neural system, which should be the lateral prefrontal cortex and posterior parietal cortex, according to the findings by McClure et al. (2004).

One of the limitations of the study may be the effect of postponed consumption, which may be relevant for subjects deciding to save money in the propositional time flow condition. A subject saving money refuses to take pleasure of using the new commodity for few days. One has to study a possible contribution of this effect experimentally, but in such case there are two other factors to consider. At the moment of the decision making in both conditions - situational and propositional future - a subject is acting in the present time and $\mathrm{s} /$ he is making a decision already knowing about the future possibility of enjoying using the new item. So, in both situational and propositional time flows one may see some kind of postponed plea- sure from consumption of the new commodity. In situational time flow it is predefined by the problem wording, in propositional time flow it is up to the subject to decide whether the pleasure of consumption can be postponed. On the other hand, Loewenstein and Thaler (1989) speak about savoring - a kind of pleasure of an anticipated event. In some cases subjects intentionally postpone the pleasant event, just to enjoy the waiting for it. The latter kind of pleasure is rather a counterargument to the limitation mentioned above.

In general, the thesis about the mind's ability to develop few cognitive representations of time flow and apply them to one and the same object or event opens a new perspective not only for studies on intertemporal decision making but also for the experimental studies on causal attribution, affective forecasting, and other aspects of human behavior regarding time dimension.

Received March 16, 2015

\section{References}

Brown, J. D. (1986). Evaluations of self and others: Self-enhancement biases in social judgments. Social Cognition, 4, 353-376.

Chandran, S., \& Menon, G. (2004). When a day means more than a year: Effects of temporal framing on judgments of health risk. Journal of Consumer Research, 31(2) (September 2004), 375-389.

Chen, M. K. (2013). The effect of language on economic behavior: Evidence from savings rates, health behaviors, and retirement assets, American Economic Review, 103(2), 690-731, doi: http://dx.doi.org/1 0.1257/aer.103.2.690

Decety, J., \& Sommerville, J. A. (2003). Shared representations between self and other: A social cognitive neuroscience view. Trends in Cognitive Sciences, N 12, 527-533.

Haslam, N., Bain, P., Douge, L., Lee, M., \& Bastian, B. (2005). More human than you: Attributing 
humanness to self and others. Journal of Personality and Social Psychology, 98, 937-950.

Kim, J., \& Nan, X. (2015). Effects of consideration of future consequences and temporal framing on acceptance of the HPV vaccine among young adults. Health Communication, 30(2), 17585. doi: 10.1080/10410236.2014.974122

Klar, Y., \& Giladi, E. E. (1997). No one in my group can be below the group's average: A robust positivity bias in favor of anonymous peers. Jour nal of Personality and Social Psychology, 73, 885-901.

Krishnamurthy, P., \& Kumar, P. (2002). Self-other discrepancies in waiting time decisions. Organizational Behaviour and Human Decision Processes, 87(2), 207-226.

Kühbinger, A. (1998). The influence of framing on risky decisions: A meta-analysis. Organizational Behaviour and Human Decision Process, 75(1), 23-55.

Levin, I. P., Schneider, S. L., \& Gaeth, G. J. (1998). All frames are not created equal: A typology and critical analysis of framing effects. Organizational Behaviour and Human Decision Process, 76(2), 149-188.

Loewenstein, G. F. (1988). Frames of mind in intertemporal choice. Management Science, 34(2), 200-214.

Loewenstein G., \& Thaler, R. H. (1989). Anomalies: Intertemporal choice. Journal of Economic Perspectives, 3(4), 181-193.

Mazur, J. (1987). An adjustment procedure for studying delayed reinforcement. In M. Commons, J. Mazur, J. Nevin, \& H. Raiffa (Eds.), The effect of delay and intervening events on reinforcement value (pp. 55-73). Hillsdale, NJ: Lawrence Erlbaum.

McClure, S. M., Laibson, D. I., Loewenstein, G., \& Cohen, J. D. (2004). Separate neural systems value immediate and delayed monetary rewards,
Science, 306, 503-507, doi: $10.1126 / \mathrm{sci}-$ ence. 1100907

Moon, P., Keasey, K., \& Duxbury, D. (1999). Mental accounting and decision making: The relationship between relative and absolute savings. Journal of Economic Behavior \& Organization, 38, 145-153.

Mowen, J. C., \& Mowen, M. M. (1991). Time and outcome valuation: Implications for marketing decision making, Journal of Marketing, 55(4), 54-62.

Polunin, O. (2009). Temporal dimension of the framing effect in topical mental accounting. Studia Psychologica, 51(4), 434-355.

Polunin, O. (2011). Temporal processes in the topical mental accounting, Studia Psychologica, 53(3), 275-291.

Polunin, O. (2014). First and the third-person perspective on a monetary saving proposition made in the future time mode, Studia Psychologica, 56(4), 253-265.

Polunin, O. (2015). Cognitive representation of situational and propositional time flow as basis for temporal framing effect in future time mode, Studia Psychologica, 57(1), 5-20.

Prelec, D., \& Loewenstein, G. (1997). Beyond time discounting. Marketing Letters, 8(1), 97-108. doi:10.1023/A:1007993512698

Read, D., Frederick, S., Burcu, Orsel, B., \& Rahman, J. (2005). Four score and seven years from now: The date/delay effect in temporal discounting. Management Science, 51(9) (Sep., 2005), 13261335.

Taylor, S. E., \& Brown, J. D. (1988). Illusion and well-being: A social psychological perspective on mental health, Psychological Bulletin, 103, 193210 .

Tversky, A., \& Kahneman, D. (1981). The framing of decisions and the psychology of choice. Science, 211, 453-458. 